\title{
Application of case-based learning in instructing clinical skills on nursing undergraduates.
}

\author{
Mengying Qi ${ }^{1}$, Qifeng Yi ${ }^{1,2 *}$, Mengyan Mo ${ }^{3}$, Hui Huang ${ }^{2}$, Yan Yang ${ }^{2}$ \\ ${ }^{1}$ Xiangya Nursing School of Central South University, Changsha, Hunan, PR China \\ ${ }^{2}$ Nursing Department, the Third Xiangya Hospital of Central South University, Changsha, Hunan, PR China \\ ${ }^{3}$ Department of Neurosurgery, the Peace Hospital of Changzhi Medical College, Changzhi, Shanxi, PR China
}

\begin{abstract}
To investigate the efficiency of case-based learning in the course of practical skills on nursing undergraduate students. A total of 147 nursing undergraduate interns from Class 2016 of our college were recruited and were assigned into experimental $(N=74)$ and control groups $(N=73)$ by random number table. Experimental group received case-based learning whilst control group were instructed by classical method. Total score and all dimension scores were significantly higher in experimental group than control group $(\mathbf{p}<\mathbf{0 . 0 5})$. A critical thinking scale showed higher scores in experimental group at all dimensions comparing to control group $(\mathbf{p}<0.01)$. Application of case-based learning in clinical practicing instruction has satisfactory effects on nursing undergraduates, as it can improve both practical skills and critical thinking potency of students.
\end{abstract}

Keywords: Case-based learning, Nursing undergraduates, Clinical practice, Skill teaching.

Accepted on October 27, 2017

\section{Introduction}

As one application discipline, nursing teaching is critically dependent on the development of nursing practical skills, which is important evidence evaluating core competency and nursing quality of students [1-3]. Clinical practice is therefore one indispensable stage for nursing students transiting from class-based learning towards clinical practice. Teaching of nursing skills is the core syllabus of clinical intern [4,5]. However, the teaching of clinical skills still mainly depends on the teacher demonstration, followed by practice under supervision and evaluation, and largely ignoring cultivation of comprehensive analysis, communication, response and critical thinking features of students [6].

With increasing number of nursing undergraduate students in China, it is critical to establish one teaching approach for clinical skills on those advanced levels of nursing students. Case-Based Learning (CBL) focuses on the participation of inclass discussion and independent judgement by students assisted under real scenario or cases, which are introduced by instructors with clinical experiences, followed by training and evaluation of practical skills and nursing knowledge $[7,8]$. In practicing $\mathrm{CBL}$, students are encouraged to perform prereading and discussion, followed by teacher-directed summary, thus developing systemic knowledge and skills from typical cases. As one open and interactive teaching method, CBL can maximally develop student's willingness for learning and creativity, activating student's mind and improving creativity idea, and guiding them to use gained knowledge to solve practical issues [9-11].

\section{Methods}

\section{Research subjects}

A total of 147 nursing intern students from April 2016 to April 2017 were recruited in the third Xiangya hospital of central south university. All participants were divided into experimental group $(\mathrm{N}=74$, including 18 males and 56 females; aging between 20 and $24 \mathrm{y}$, average age $=22.34 \pm 1.15 \mathrm{y}$ ) and control group ( $\mathrm{N}=73$, including 13 males and 60 females, aging between 20 and $24 \mathrm{y}$, average age $=22.18 \pm 1.27 \mathrm{y}$ ). No significant difference was found in sex, age or grade between two groups $(\mathrm{p}>0.05)$.

\section{Teaching methods}

Completion of case database: Teaching syllabus was used to identify practical items, including basic nursing practice such as intravenous infusion, oxygen inhaling, intramuscular injection, subcutaneous testing, Cardiopulmonary Resuscitation (CPR), axis turning over, urethral catheterization, edema, plus specialty operations such as drainage cleaning, electrocardiogram monitor, and neonatal umbilical care. About 5-10 typical clinical cases were recruited for each operation skill, and each case generally covers one or two operation skills. All clinical cases were collected from hospital 
departments, covering both typical and special cases, and were discussed by clinicians including manifestation, body signs, treatment, patient's demographic condition, culture background or working history to reflect changes during disease course. One basic operation was identified from each department. The design of whole CBL program is based on the consideration of teaching depth, class organization. The teaching process is carried ensuring patient's safety and privacy.

One typical cases of cardiology: One 65 y male was admitted by emergency clinic due to "Pain in post-sternum, accompanying with vomiting, cold sweating and felling of impeding death for one hour after morning drilling". Primary examination showed body temperature $(\mathrm{T})=37.6^{\circ} \mathrm{C}$, pulsing frequency $=40$ per $\mathrm{min}$, respiration frequency $=16$ per min, blood pressure $=12.0 / 8.0 \mathrm{kPa}$. Patient had abundant sweating, whitening face, mild cyanose, and painful facial expression. ECG showed elevated arc back of ST segment at II, III and aVF electrode, with sparsely premature ventricular contraction. Question: (1) What is the most likely diagnosis of this patient? (2) What is the primary counter-measures for on-duty nurse?

\section{Evaluation of training}

During $4 \mathrm{w}$ training in all departments, control group received classical "demonstration-practice-evaluation" approach, including teacher demonstration, followed by student practice and examination. In experimental group, individual student received $\mathrm{CBL}$ forms at second week after enrolling, and was trained and evaluated at fourth week. Under full evaluation and compliance of patient condition, plus patient's consent, nursing interns in experimental group performed operations on patients under supervision of mentors. For those cases incompliance for direct practice, interns were instructed to play as patient, clinician and nurse to cultivate capacity for solving clinical issues. Teaching coordinator then organized central teaching and summary of all students.

For the previous sample case in cardiology, patient diagnosis was acute inferior myocardial infarction. Counter-measures consisted of: (1) Absolutely bed resting; (2) Oxygen inhaling; (3) ECG monitoring; (4) Anti-arhythmia or thrombolysis treatment under prescription; (5) Opening of venous flow to collect samples; (6) Psychological caring; (7) Informed intervention surgery room for further operation. In this case, ECG monitoring and oxygen inhaling were listed as practical skills for evaluation.

\section{Evaluation tools}

Skill evaluations: Uniformly revised scale system was used for scoring on both control and experimental groups. A 100point system was adopted in include both basic knowledge (30 points) and practical skills (70 points). The revised scaling system has transformed from classical "skill-focusing" system into comprehensive evaluation including basic knowledge, practical skills, case analysis, health education, mock emergency medicine, communication skill and professional attitudes. Averaged scores were calculated from all departments.

Evaluation of critical thinking potency: California Critical Thinking Deposition Inventory-Chinese Version (CCTDI-CV) was adopted to measure seven dimensions (truth seeking, open thinking, analytical skills, systemic potency, confidence of critical thinking, novelty of knowledge and maturity of recognition) from 70 items, each of which was scaled in Likert 6-point system. Higher score indicates more significant critical thinking tendency, as those with total score $\leq 210$ points indicated negative trends of critical thinking, those between 211 and 280 indicated ambiguous tendency, those between 281 and 350 points were identified as positively critical thinking deposition, and those having total score higher than 350 points showed strong critical thinking skills. The overall effectiveness of CCTDI-CV was 0.90, and coefficient at all dimensions was between 0.55 and 0.77 . Currently this system was widely used to evaluate thinking tendency of nursing students [12-14].

\section{Statistical analysis}

SPSS13.0 software was used for data input and analysis. Skill examination results were presented as mean \pm Standard Deviation (SD). Independent sample student t-test was used to compare between-group difference before and after intervention. Paired sample t-test was used to analyse in-group difference. A statistical significance was identified when $\mathrm{p}<0.05$ or $\mathrm{p}<0.01$.

\section{Results}

\section{Comparative analysis of skill examination on nursing undergraduates after intern training}

Experimental and control groups showed significant difference in total score, practical skill, basic knowledge, problem analysis, communication skill and professional attitudes $(p<0.05)$. Experimental group had better total score than control group $(\mathrm{p}<0.05$, Table 1$)$.

\section{Comparative analysis of critical thinking capacity between two groups of nursing undergraduate interns}

Total scores of critical thinking capacity of both groups all showed improvement during internship $(\mathrm{p}<0.05)$. Experimental group showed more potent increase of total scores than control group $(\mathrm{p}<0.05)$. An interaction effect existed between time and group factor $(\mathrm{p}<0.05)$. Table 2 showed total score and all dimension scale of critical thinking on two groups of nursing interns before and after education.

Table 1. Comparison of skill evaluation results between two groups of nursing students.

\begin{tabular}{lllll}
\hline Item & Experiment & Control & t value & P value \\
\hline Total score & $90.3 \pm 1.8$ & $84.2 \pm 4.3$ & 5.96 & $<0.05$ \\
\hline Basic knowledge $(20 \%)$ & $17.2 \pm 1.7$ & $15.8 \pm 1.8$ & 2.14 & $<0.05$ \\
\hline
\end{tabular}




\begin{tabular}{|c|c|c|c|c|}
\hline Practical skill (20\%) & $16.3 \pm 2.4$ & $14.2 \pm 2.6$ & 3.82 & $<0.05$ \\
\hline Nursing evaluation (10\%) & $9.3 \pm 1.2$ & $8.5 \pm 0.9$ & 4.52 & $<0.05$ \\
\hline Case analysis $(10 \%)$ & $9.1 \pm 1.6$ & $8.6 \pm 1.1$ & 4.52 & $<0.05$ \\
\hline Health education (10\%) & $8.7 \pm 1.5$ & $8.1 \pm 1.1$ & 4.52 & $<0.05$ \\
\hline $\begin{array}{l}\text { Mocked emergency aid } \\
(10 \%)\end{array}$ & $9.2 \pm 1.7$ & $8.7 \pm 1.1$ & 4.52 & $<0.05$ \\
\hline Communication skill (10\%) & $8.6 \pm 1.2$ & $8.4 \pm 1.3$ & 1.59 & $<0.05$ \\
\hline Professional attitude (10\%) & $8.9 \pm 0.8$ & $8.5 \pm 1.0$ & 1.06 & $<0.05$ \\
\hline
\end{tabular}

Table 2. Comparison of critical thinking ability before and after in two groups of nursing interns.

\begin{tabular}{|c|c|c|c|c|}
\hline & $\begin{array}{l}\text { Experiment } \\
(n=74)\end{array}$ & Control $(n=73)$ & $\begin{array}{l}\mathrm{t} \\
\text { value }\end{array}$ & $P$ value \\
\hline Total score & $249.45 \pm 15.66$ & $250.04 \pm 14.87$ & 0.05 & 0.961 \\
\hline \multicolumn{5}{|l|}{ Before intervention } \\
\hline After intervention & $313.59 \pm 14.63$ & $285.88 \pm 15.87$ & 2.43 & $0.019^{*}$ \\
\hline t value & -3.71 & -3.22 & & \\
\hline$P$ value & 0 & 0 & & \\
\hline Seeking for truth & $36.25 \pm 5.66$ & $35.68 \pm 4.63$ & 0.17 & 0.864 \\
\hline \multicolumn{5}{|l|}{ Before intervention } \\
\hline After intervention & $47.13 \pm 4.26$ & $41.80 \pm 3.87$ & 3.41 & $0.000^{*}$ \\
\hline t value & -6.33 & -4.58 & & \\
\hline$P$ value & 0 & 0 & & \\
\hline Open thinking & $35.08 \pm 6.40$ & $34.76 \pm 5.52$ & 0.17 & 0.864 \\
\hline \multicolumn{5}{|l|}{ Before intervention } \\
\hline After intervention & $46.60 \pm 5.41$ & $40.56 \pm 4.81$ & 3.41 & $0.000^{*}$ \\
\hline $\mathrm{t}$ value & -6.33 & -3.58 & & \\
\hline$P$ value & 0 & 0 & & \\
\hline Analytical skills & $38.64 \pm 1.29$ & $39.20 \pm 6.12$ & 1.29 & 0.203 \\
\hline \multicolumn{5}{|l|}{ Before intervention } \\
\hline After intervention & $46.56 \pm 1.29$ & $42.60 \pm 5.63$ & 4. 70 & $0.000^{*}$ \\
\hline t value & -7.27 & -5.93 & & \\
\hline$P$ value & 0 & 0 & & \\
\hline Systemic thinking & $36.52 \pm 1.26$ & $36.76 \pm 5.51$ & -0.61 & 0.545 \\
\hline \multicolumn{5}{|l|}{ Before intervention } \\
\hline After intervention & $45.04 \pm 1.14$ & $41.92 \pm 6.41$ & 5.85 & $0.000^{*}$ \\
\hline $\mathrm{t}$ value & -8.38 & -4.48 & & \\
\hline$P$ value & 0 & 0 & & \\
\hline $\begin{array}{l}\text { Confidence of critical } \\
\text { thinking }\end{array}$ & $33.60 \pm 3.66$ & $34.08 \pm 6.42$ & 0.52 & 0.606 \\
\hline
\end{tabular}

Before intervention

$\begin{array}{lllll}\text { After intervention } & 43.90 \pm 5.32 & 40.60 \pm 5.43 & 2.83 & 0.007^{*}\end{array}$

\begin{tabular}{|c|c|c|c|c|}
\hline $\mathrm{t}$ value & -10.74 & -5.55 & & \\
\hline$P$ value & 0 & 0 & & \\
\hline Seeking for knowledge & $35.04 \pm 5.68$ & $34.36 \pm 5.77$ & 0.42 & 0.676 \\
\hline \multicolumn{5}{|l|}{ Before intervention } \\
\hline After intervention & $42.08 \pm 3.66$ & $38.90 \pm 5.35$ & 4.21 & $0.000^{*}$ \\
\hline $\mathrm{t}$ value & -4.22 & -2.51 & & \\
\hline$P$ value & 0 & 0 & & \\
\hline $\begin{array}{l}\text { Maturation } \\
\text { recognition }\end{array}$ & $34.32 \pm 5.48$ & $35.20 \pm 5.27$ & 0.08 & 0.937 \\
\hline \multicolumn{5}{|l|}{ Before intervention } \\
\hline After intervention & $42.28 \pm 3.70$ & $38.50 \pm 6.08$ & 3.92 & $0.000^{*}$ \\
\hline$t$ value & -4.76 & -2.28 & & \\
\hline$P$ value & 0 & 0 & & \\
\hline
\end{tabular}

\section{Discussion}

The development of modern nursing theory and practical requirement has made more requests for nursing education. Some scholars indicated that certain patients, although having excellent score in knowledge, but lacking effective measurements when facing real patients. The revolution of teaching approach to improve critical thinking of clinical undergraduates is thus of critical importance. During CBL education, clinical cases were used as the carrier for medical knowledge and practical skills, and patients were located in real-scenario of clinical practice filling with thinking from all dimensions to inspire them for learning interest and to solve problems [15]. CBL can guide students for hypothesis, questioning, reasoning, discussion, and investigation of objective reality based on previous knowledge, thus developing student potential competency [16]. In this study, CBL effective improved practical skills of nursing undergraduates compared to classical teaching approach. CBL improved student's skills in basic knowledge, practical skills, nursing evaluation, case analysis, health education, mocked emergency aid, communication skills, and professional attitude. Such roleplayed approach and scenario-based teaching can guide students into unique medical case, in which students are allowed to actively learn, thus improving their skills of analyzing and solving problems. Moreover, $\mathrm{CBL}$ approach is more interesting than in-class teaching, benefiting the understanding of basic pathology and ideas of disease. Groupbased learning approach can also improve student team-work spirit, professional attitude and communication skills.

CBL generally focuses on active learning of knowledge and the predominant role of student in education process [11]. All learning cases were derived from real scenarios in clinics, and thus requiring students to combine basic knowledge with realscenario. Relative high load of literature review can cultivate student's ability to actively search for information, thus significantly develop the skill of analyzing and solving problems, in addition to communication skill and creativity 
attitude, eventually improving clinical based thinking competency and skills of nursing interns [4,9]. This study also revealed that $\mathrm{CBL}$ could improve critical thinking ability of students, suggesting that CBL-method in combined with casedirected study significantly improved core competency of nursing undergraduates in solving clinical problems, and made them more competent for clinical practice in future [5].

As one revolution of class teaching, CBL has transformed traditional "passive learning" of students into active learning, which raised higher requirement for instructors, who must accurately grab key knowledge of syllabus, focus on research progress of nursing, and must have certain clinical experiences. The selection of clinical cases in CBL should consider typical features, complete and reality, and meanwhile guiding students for further discussion $[11,16,17]$. Although CBL has multiple advantages, it cannot completely replace the role of in-class teaching. CBL should be combined with other teaching approaches in order to maximally improve teaching and learning efficiency of nursing education [18].

\section{Conclusion}

CBL has relatively satisfactory effects in practical skill teaching of nursing undergraduates, and can improve the operation skills and critical thinking deposition of students.

\section{Acknowledgments}

This work was supported by Foundation of Research on Undergraduate Teaching Reform of Central South University (2015-87).

\section{References}

1. Aiken LH, Sloane D, Griffiths P, Rafferty AM, Bruyneel L, McHugh M, Maier CB, Moreno-Casbas T, Ball JE, Ausserhofer D, Sermeus W. Nursing skill mix in European hospitals: cross-sectional study of the association with mortality, patient ratings, and quality of care. BMJ Qual Saf 2017; 26: 559-568.

2. Ireland CG, Pigott EM, Tolley EA, Self TH. Teachinglearning experience regarding skill in using inhalers: medical students teaching nursing students. J Nurs Educ 2017; 56: 120-122.

3. Maehle V, Cooper K, Kirkpatrick P. Absolute clinical skill decay in the medical, nursing and allied health professions: a scoping review protocol. JBI Datab Sys Rev Implement Rep 2017; 15: 1522-1527.

4. Stephenson E, Salih Z, Cullen DL. Advanced practice nursing simulation for neonatal skill competency: a pilot study for successful continuing education. J Contin Educ Nurs 2015; 46: 322-325.

5. Merrick E, Duffield C, Baldwin R, Fry M. Nursing in general practice: organizational possibilities for decision latitude, created skill, social support and identity derived from role. J Adv Nurs 2012; 68: 614-624.
6. Shin K, Jung DY, Shin S, Kim MS. Critical thinking dispositions and skills of senior nursing students in associate, baccalaureate, and RN-to-BSN programs. J Nurs Educ 2006; 45: 233-237.

7. Gholami M, Saki M, Toulabi T, Kordestani Moghadam P, Hossein Pour AH, Dostizadeh R. Iranian nursing students experiences of case-based learning: a qualitative study. J Prof Nurs 2017; 33: 241-249.

8. Chan AW, Chair SY, Sit JW, Wong EM, Lee DT, Fung OW. Case-based web learning versus face-to-face learning: a mixed-method study on university nursing students. J Nurs Res 2016; 24: 31-40.

9. Aluisio AR, Daniel P, Grock A, Freedman J, Singh A, Papanagnou D, Arquilla B. Case-based learning outperformed simulation exercises in disaster preparedness education among nursing trainees in India: a randomized controlled trial. Prehosp Disaster Med 2016; 31: 516-523.

10. Hong S, Yu P. Comparison of the effectiveness of two styles of case-based learning implemented in lectures for developing nursing students critical thinking ability: A randomized controlled trial. Int J Nurs Stud 2017; 68: 16-24.

11. Linnard-Palmer L. The use of simulation for pediatric oncology nursing safety principles: ensuring competent practice through the use of a mnemonic, chemotherapy road maps and case-based learning. J Pediatr Nurs 2012; 27: 283-286.

12. Kong LN, Qin B, Zhou YQ, Mou SY, Gao HM. The effectiveness of problem-based learning on development of nursing students critical thinking: a systematic review and meta-analysis. Int J Nurs Stud 2014; 51: 458-469.

13. Naber J, Wyatt TH. The effect of reflective writing interventions on the critical thinking skills and dispositions of baccalaureate nursing students. Nurse Educ Today 2014; 34: 67-72.

14. Wangensteen S, Johansson IS, Bjorkstrom ME, Nordstrom G. Research utilisation and critical thinking among newly graduated nurses: predictors for research use. A quantitative cross-sectional study. J Clin Nurs 2011; 20: 2436-2447.

15. Yoo MS, Park HR, Effects of case-based learning on communication skills, problem-solving ability, and learning motivation in nursing students. Nurs Health Sci 2015; 17: 166-172.

16. McMahon MA, Christopher KA. Case study method and problem-based learning: utilizing the pedagogical model of progressive complexity in nursing education. Int J Nurs Educ Scholarsh 2011; 8.

17. Yoo MS, Park JH. Effect of case-based learning on the development of graduate nurses problem-solving ability. Nurse Educ Today 2014; 34: 47-51.

18. Kantar LD, Massouh A. Case-based learning: What traditional curricula fail to teach. Nurse Educ Today 2015; 35: 8-14. 
Application of case-based learning in instructing clinical skills on nursing undergraduates

\section{*Correspondence to}

Qifeng Yi

Nursing Department

The Third Xiangya Hospital of Central South University

Xiangya Nursing School of Central South University

PR China 